\title{
REVIEWS
}

\section{Passive immunotherapy of viral infections: 'super-antibodies' enter the fray}

\section{Laura M. Walker ${ }^{1}$ and Dennis R. Burton ${ }^{2-4}$}

Abstract | Antibodies have been used for more than 100 years in the therapy of infectious diseases, but a new generation of highly potent and/or broadly cross-reactive human monoclonal antibodies (sometimes referred to as 'super-antibodies') offers new opportunities for intervention. The isolation of these antibodies, most of which are rarely induced in human infections, has primarily been achieved by large-scale screening for suitable donors and new single B cell approaches to human monoclonal antibody generation. Engineering the antibodies to improve half-life and effector functions has further augmented their in vivo activity in some cases. Super-antibodies offer promise for the prophylaxis and therapy of infections with a range of viruses, including those that are highly antigenically variable and those that are newly emerging or that have pandemic potential. The next few years will be decisive in the realization of the promise of super-antibodies.

${ }^{1}$ Adimab LLC, Lebanon, New Hampshire 03766, USA. ${ }^{2}$ Department of Immunology and Microbiology, Center for HIV/AIDS Vaccine Immunology and Immunogen Discovery, The Scripps Research Institute, La Jolla, California 92037, USA 3 International AIDS Vaccine Initiative Neutralizing Antibody Center, The Scripps Research Institute, La Jolla, California 92037, USA. ${ }^{4}$ Ragon Institute of Massachusetts General Hospital, Massachusetts Institute of Technology and Harvard University. Cambridge, Massachusetts 02139, USA.

laura.walker@adimab.com burton@scripps.edu
The use of antibodies to ameliorate the adverse clinical effects of microbial infection can be traced back to the late 19th century and the work of von Behring and Kitasato on the serum therapy of diphtheria and tetanus (reviewed in REFS 1,2). In these settings, the antibodies act to neutralize bacterial toxins. Therapies followed in which serum antibodies were targeted directly against bacterial and then viral pathogens. For viral pathogens, enriched polyclonal IgG molecules from immunized animals were shown to be effective in prophylaxis, and even prophylaxis after exposure, for a number of viruses, including hepatitis A virus, hepatitis B virus, hepatitis $\mathrm{C}$ virus, herpes simplex virus, measles virus, rabies virus, respiratory syncytial virus (RSV), smallpox virus and varicella zoster virus. In general, the effectiveness of antibody preparations declined with the duration of infection such that they were often regarded as poor therapeutic options. Of course, the major antiviral strategy of the 20th century was vaccination.

Over the latter part of the 20th and early part of the 21st century, there have been major developments in our understanding of antibodies and our ability to manipulate them. The advent of hybridoma technology in 1976 provided a reliable source of mouse monoclonal antibodies (mAbs), the first impact of which was not on antibody therapy but on the characterization of cells through the definition of cell surface markers. Broad implementation of mAbs in therapy had to wait until the development of humanized mouse antibodies and then the generation of fully human antibodies by various techniques described below. Such antibodies have been largely applied in the fields of oncology and autoimmunity. Only a single antiviral $\mathrm{mAb}$, the RSV-specific antibody palivizumab, is in widespread clinical use. The reasons for this have been discussed elsewhere ${ }^{1,3-6}$, although perhaps the most important reasons are the fairly high cost of the production of mAbs, the difficulties of administration and a belief that antibodies are largely effective only in a prophylactic setting, which can be achieved for many viruses by vaccination.

However, as we discuss here, an increasing number of antiviral antibodies with quite remarkable properties in terms of potency and/or cross reactivity with other viruses or strains of the same virus are being isolated. These so-called super-antibodies are changing our understanding of what we can hope to achieve with antibodies against microbial infection in the clinic. Increased potency can greatly reduce the unit costs of treatment, make alternative routes of administration feasible and extend the effective half-life of the antibody. Increased cross reactivity can allow us to consider targeting multiple viruses with single antibodies. Antibody engineering can impact both potency and cross reactivity and can greatly extend the half-life of super-antibodies.

In this Review, we discuss how new approaches have fuelled the identification of super-antibodies, where and how such antibodies may be best applied and future directions for the field. 


\section{Super-antibody discovery}

Many acute viral infections induce robust neutralizing antibody responses in the large majority of individuals. In general, these viruses show little evidence for evasion of antibody responses, and we have referred to them as 'evasion lite' viruses?. Typically, they either display limited antigenic variability in their surface protein (or proteins) or show considerable variability but nevertheless express immunodominant, conserved epitopes. Examples of viruses in this category include measles virus, poliovirus, chikungunya virus and $\mathrm{RSV}^{8-11}$. The life cycle of these viruses presumably does not dictate immune evasion. For these types of viruses, the isolation of super-antibodies from immune donors has been achieved in a fairly straightforward manner,8,92-14. However, some viruses have evolved mechanisms to evade effective neutralizing antibody responses (termed 'evasion strong' viruses) and induce such responses at much lower levels. Effective responses in the context of infection with highly antigenically variable viruses refers not only to their neutralization potency but also to their effectiveness against diverse circulating global isolates, often referred to as breadth. For these viruses - including HIV, influenza virus, Ebola virus and Lassa virus - only a proportion of infected individuals, sometimes quite small, will generate broad and potent neutralizing antibody responses ${ }^{15-21}$. Furthermore, within these individuals, potent broadly neutralizing antibody (bnAb) specificities generally constitute only a small fraction of the antigen-specific memory B cell pool.

For example, only a small percentage of HIV-infected individuals develop broad and potent serum responses over time, and B cell cloning efforts have demonstrated that bnAbs generally comprise $<1 \%$ of the HIV envelope (Env)-specific memory B cell repertoire ${ }^{22}$. Although there are probably multiple factors that contribute to the low abundance of bnAbs within these individuals, the intrinsic nature of the viral Env protein likely has a key role. The HIV Env protein has evolved a multitude of mechanisms to evade bn Ab responses, including decoy forms of Env, enormous antigenic variability, an evolving glycan shield, immunodominant and variable epitopes and poorly accessible conserved epitopes ${ }^{23}$. Furthermore, most HIV-specific bnAbs incorporate unusual features for epitope recognition, such as uncommonly long (or short) complementarity determining region 3 (CDR3) loops, insertions and deletions, tyrosine sulfation and extensive somatic hypermutation, that likely also contribute to the rarity and delayed development of bnAbs during natural infection ${ }^{24-26}$.

In the case of influenza virus infection, the vast majority of neutralizing antibodies elicited by infection or vaccination bind to variable epitopes within the haemagglutinin (HA) globular head of the viral particles and display strain-specific neutralizing activity ${ }^{27}$. Influenza virus-specific bnAbs typically target the conserved HA stem, but this region has variable immunogenicity ${ }^{28-31}$. The relatively low frequency of bnAbs against the HA stem is perhaps due to the typically tight packing of HA trimers on the virus surface, which may limit antibody accessibility to this region. For Ebola and
Lassa viruses, extensive glycosylation on the surface Env proteins results in masking of conserved neutralizing epitopes ${ }^{15,32}$. In cases where super-antibodies are present at low frequency within immune repertoires, large-scale donor screening and high-throughput $B$ cell isolation platforms have proved to be critical for the discovery of super-antibodies. Over the past several years, technological advances in these two areas have led to the identification of large numbers of super-antibodies, mostly from infected individuals, against a plethora of viral pathogens.

Large-scale donor screening. In the case of HIV, which has served as a prototype virus for many studies in this field $^{33}$, systematic selection of donors with broadly neutralizing serum responses has proved to be critical for the identification of super-antibodies. Before 2009, the HIV field had been operating with a handful of bnAbs, all of which were limited either in breadth or in potency ${ }^{34}$. A number of factors complicated the identification of bnAbs, including the inefficiency of traditional approaches to $\mathrm{mAb}$ discovery, the small fraction of B cells that secrete bnAbs and the limited availability of samples from donors who had developed broad and potent neutralizing serum responses. Beginning in 2005, the problem of limited samples was addressed by establishing donor screening programmes to identify HIVinfected individuals with broadly neutralizing serum responses to serve as source material for the generation of bnAbs ${ }^{18,19,35,36}$. In one of the largest studies, $~ 1,800$ HIV-infected individuals from Australia, Rwanda, Uganda, the United Kingdom and Zambia were screened for broadly neutralizing sera using a reduced pseudovirus panel representative of global circulating HIV isolates $^{19}$. A subset of individuals, termed 'elite neutralizers', was identified that exhibited exceptionally broad and potent neutralizing serum responses and was therefore prioritized for bnAb isolation.

Over the past 8 years, mining of these and similar samples has led to the identification of dozens of remarkably broad and potent HIV super-antibodie ${ }^{37-41}$. Careful selection of donors with desirable serum profiles has also enabled the isolation of rare super-antibodies to influenza virus, RSV, human metapneumovirus (HMPV), rabies virus and Zika virus ${ }^{12,42-44}$. For example, the pan-influenza A virus-neutralizing mAb FI6 and the RSV and HMPV cross-neutralizing $\mathrm{mAb}$ MPE8 were isolated from donors who were selected on the basis of their strong heterotypic serum responses ${ }^{12,42}$. Similarly, two pan-lyssavirus-neutralizing mAbs, called RVC20 and RVC58, were isolated from the memory B cells of four donors who exhibited potent serum-neutralizing activity against multiple lyssavirus species ${ }^{43}$.

High-throughput human B cell isolation technologies. Human antiviral neutralizing $m A b s$ have been isolated using various different technologies, including combinatorial display libraries, human immunoglobulin transgenic mice and single B cell isolation methods (FIG. 1). Although all of these technologies have proved valuable for $\mathrm{mAb}$ generation, the recent burst in super-antibody 


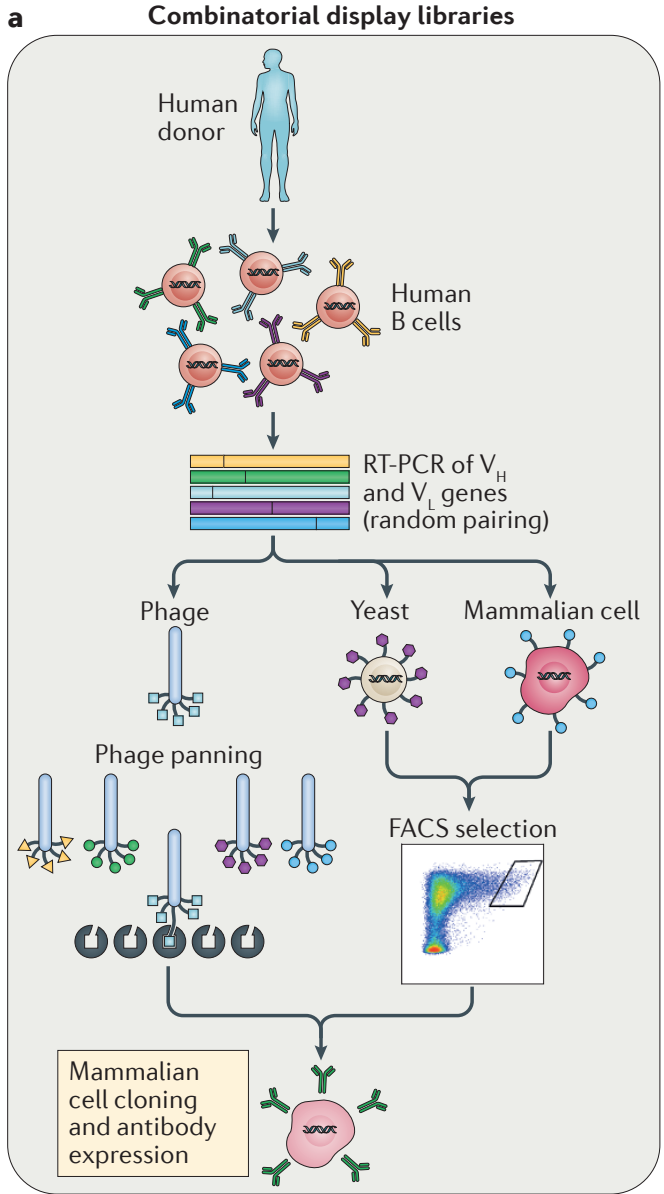

Figure 1 | Technologies for monoclonal antibody generation. a|Combinatorial display libraries. Human antibody heavy-chain and light-chain genes are amplified by reverse transcription (RT)-PCR, and antibody fragments are displayed on the surface of a particle or cell in which the antibody genes are found (such as phage, yeast or mammalian cells ${ }^{142-145}$ ). Successive rounds of enrichment are performed to select for clones that bind to the target antigen. Genes encoding antibodies of interest are cloned into human lgG expression vectors to produce monoclonal antibodies (mAbs). b|Human immunoglobulin transgenic mice are generated by introducing human immunoglobulin loci into the mouse genome $\mathrm{e}^{146,147}$. Upon immunization, the transgenic mice produce fully human antigen-specific antibodies. The $B$ cells harvested from the immunized mice are fused with myeloma cells to generate antibody-secreting hybridomas, which are then screened for binding or functional activity. c| Single B cell cloning. Antigen-specific memory B cells or plasmablasts are single-cell sorted by flow cytometry, and cognate heavy-chain $(\mathrm{VH})$ and light-chain $(\mathrm{VL})$ variable genes are amplified by single-cell $\mathrm{PCR}^{57,58,148}$. The antibody variable genes are cloned into human $\mathrm{lg} G$ expression vectors to produce mAbs. d|Memory B cell immortalization. Memory B cells are immortalized by Epstein-Barr virus (EBV), and B cell culture supernatants are screened for binding or functional activity ${ }^{149}$. Positive cultures are subcloned by limiting dilution. e|Memory B cell culture. Single B cells are activated and cultured, and B cell supernatants are screened for binding or functional activity 37,150 . Antibody variable genes are amplified from clones of interest by PCR and cloned into human $\mathrm{lg} G$ expression vectors to produce mAbs. FACS, fluorescence-activated cell sorting. b
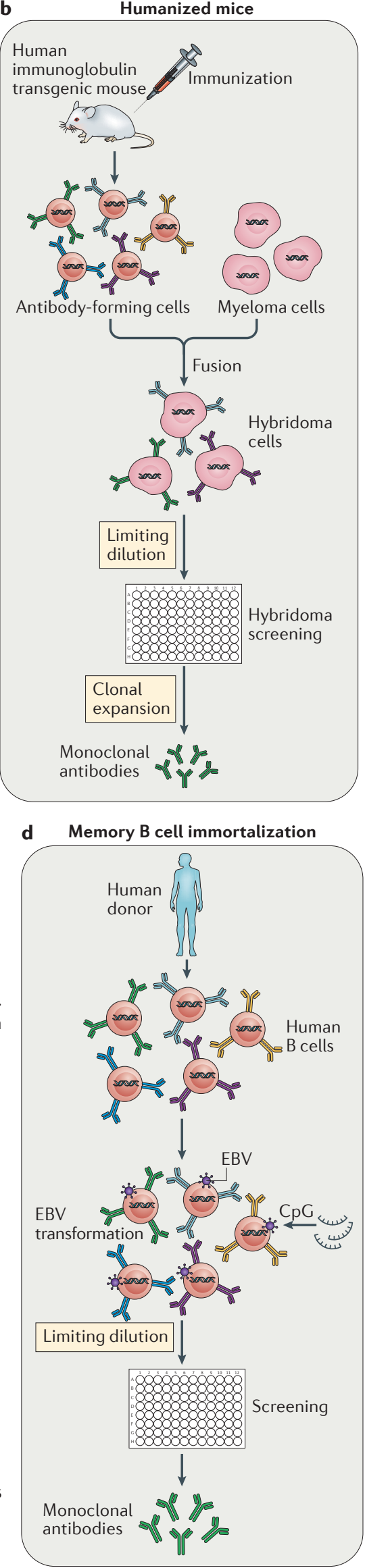
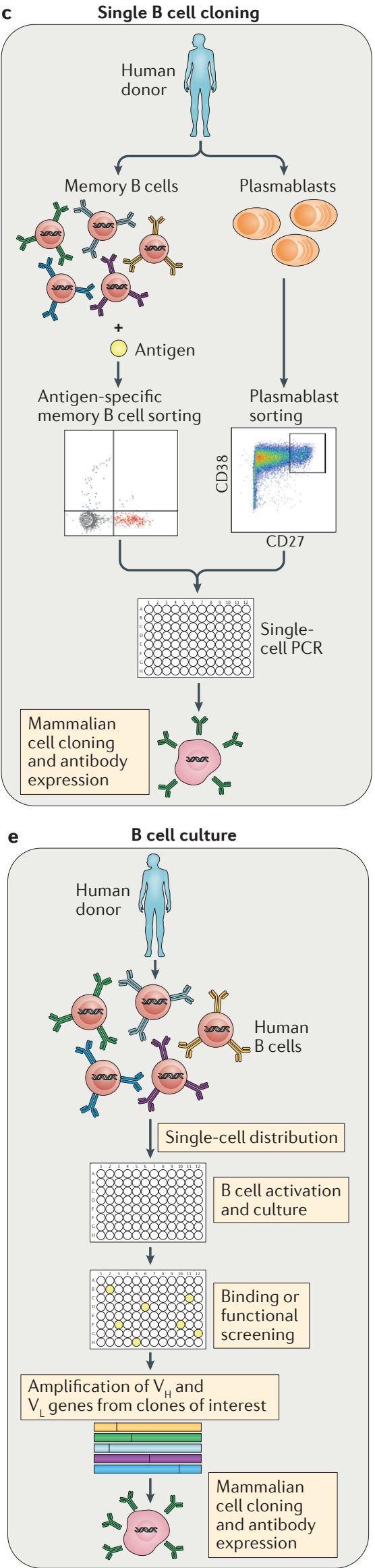
discovery has primarily been driven by advances in single B cell-based methods. There are several possible reasons for this, including inefficiencies in combinatorial library generation and interrogation (leading to the loss of rare clones), altered binding characteristics of antibody fragments produced in heterologous expression systems (for example, Escherichia coli or yeast), constraints on the generation of suitable recombinant antigens for immunization or library selections, the loss of native heavy-chain and light-chain pairing during immune library generation and inherent differences between the adaptive immune systems of humanized mice and humans ${ }^{45}$.

Several technological breakthroughs in the B cell cloning arena have been most critical in fuelling super-antibody identification. One of these advances came in 2009, when direct functional screening of thousands of B cell clones from an HIV elite neutralizer led to the isolation of two super-antibodies, PG9 and PG16, that were approximately an order of magnitude more potent than first-generation bnAbs ${ }^{37}$. Notably, PG9 and PG16 bind poorly to recombinant Env proteins and thus would not have been identified without direct functional screening of B cell supernatants. To date, many dozens of HIV-specific bnAbs targeting a diverse range of epitopes have been identified using functional screening approaches ${ }^{39,46-48}$. Highly potent super-antibodies to RSV, HMPV, Lassa virus and human cytomegalovirus (HCMV) have also been discovered using high-throughput functional screening technologies ${ }^{12,13,49,50}$ (TABLE 1).

Similar to PG9 and PG16, these super-antibodies were isolated by screening B cell supernatants on the basis of their capacity to neutralize infection in vitro and were subsequently found to react poorly with currently available recombinant Env proteins. In the case of RSV, this approach led to the isolation of the highly potent $\mathrm{mAb}$ D25, which binds to an epitope that is exclusively expressed on the prefusion conformation of RSV fusion glycoproteins (F proteins) ${ }^{49,51}$. An engineered variant of mAb D25 (MEDI8897), which exhibits 50-100 times greater neutralization potency than palivizumab, is now being tested in clinical trials for the prevention of RSV-associated disease in high-risk infants. A second RSV prefusion F protein-specific super-antibody, which cross-neutralizes several different paramyxoviruses, including HMPV, was also isolated by screening B cell supernatants for neutralizing activity ${ }^{12}$ (TABLE 1).

In the case of HCMV, direct functional screening enabled the isolation of highly potent super-antibodies specific for conformational epitopes within the gH-gLUL128-UL130-UL131A pentamer complex, which was not previously known to be a target for neutralizing antibodies ${ }^{13}$. Direct functional screening approaches have also led to the discovery of potent super-antibodies to Middle East respiratory syndrome coronavirus (MERS$\mathrm{CoV})$, Ebola virus, influenza virus, chikungunya virus, rabies virus and the poxvirus family ${ }^{9,42,43,52-56}$. Notably, in the case of MERS-CoV, only $1 \mathrm{~B}$ cell culture out of 4,600 screened showed neutralizing activity ${ }^{53}$. Similarly, the pan-influenza A virus-neutralizing mAb FI6 was isolated by testing 104,000 plasma cells from eight immune donors ${ }^{42}$. Finally, only 2 of $500 \mathrm{mAbs}$ that were selected on the basis of their ability to neutralize rabies virus showed cross-neutralizing activity against multiple lyssavirus species ${ }^{43}$. These examples clearly illustrate that exhaustive interrogation of immune repertoires is often required for the identification of rare cross-neutralizing super-antibodies.

A second breakthrough in the HIV antibody field followed the development of technology for antigenspecific single B cell sorting ${ }^{57-59}$. This approach, coupled with the use of rationally designed Env probes, allowed for the discovery of two new potent HIV-specific bnAbs that target the conserved CD4 binding site ${ }^{60,61}$ (TABLE 1). Following this discovery, several other potent bnAbs against the CD4 binding site were isolated through the use of similar approaches ${ }^{38,62,63}$. Recently, advances in the generation of recombinant native-like HIV Env trimers have enabled the identification of exceptionally potent 'PG9-class' bnAbs ${ }^{40}$.

Many HIV super-antibodies have now been generated with the use of single B cell sorting technology $38,40,60,62,63$. The use of fluorescently labelled probes to sort antigen-specific memory B cells has also enabled the discovery of highly potent super-antibodies to Ebola virus, RSV, human papilloma virus (HPV), Zika virus and influenza virus ${ }^{11,30,31,44,64,65}$. In the case of Ebola virus, a large-scale single $\mathrm{B}$ cell cloning effort led to the isolation of several hundred mAbs specific for Ebola virus envelope glycoprotein (GP), two of which showed potent pan-Ebola virus-neutralizing activity and protective efficacy ${ }^{64,66}$. A similar effort in the RSV field allowed for the isolation of several prefusion F-protein-specific mAbs that show over 100 times more potent neutralizing activity than palivizumab ${ }^{11}$. In addition, multiple groups have used clever dual-antigen labelling strategies to identify potent bnAbs to HIV, influenza virus, Ebola virus and $\mathrm{HPV}^{30,31,40,65,67,68}$. The structures of several super-antibodies bound to their viral targets are shown in FIGURE 2. Finally, a recent report showed that bnAbs to HIV can be readily elicited in cows through the use of a single Env trimer immunogen and that this induction depends on the long heavy-chain CDR3 loops of the bovine immunoglobulin repertoire ${ }^{67}$. It is possible that this repertoire may provide advantages in generating super-antibodies against other pathogens.

Vaccination or infection-induced antibody-secreting cell (ASC) responses have also proved to be a rich source of antigen-specific antibodies. Following early studies that showed that a transient but large population of ASCs appears in peripheral blood 5-7 days after tetanus toxoid booster vaccination ${ }^{69}$, it was shown that influenza virus vaccination produced a similar ASC response and that the large majority of $\mathrm{mAbs}$ cloned from these cells bound with high affinity to influenza virus, providing a proof of concept that the ASC response could be exploited to rapidly generate antigen-specific antibodies against any immunizing antigen ${ }^{70}$. To date, plasmablast cloning has led to the isolation of mAbs against many different viruses, including dengue virus, Zika virus, $\mathrm{HIV}$, influenza virus, vaccinia virus and rotavirus ${ }^{29,71-76}$. 
Table 1 | Antiviral super-antibodies

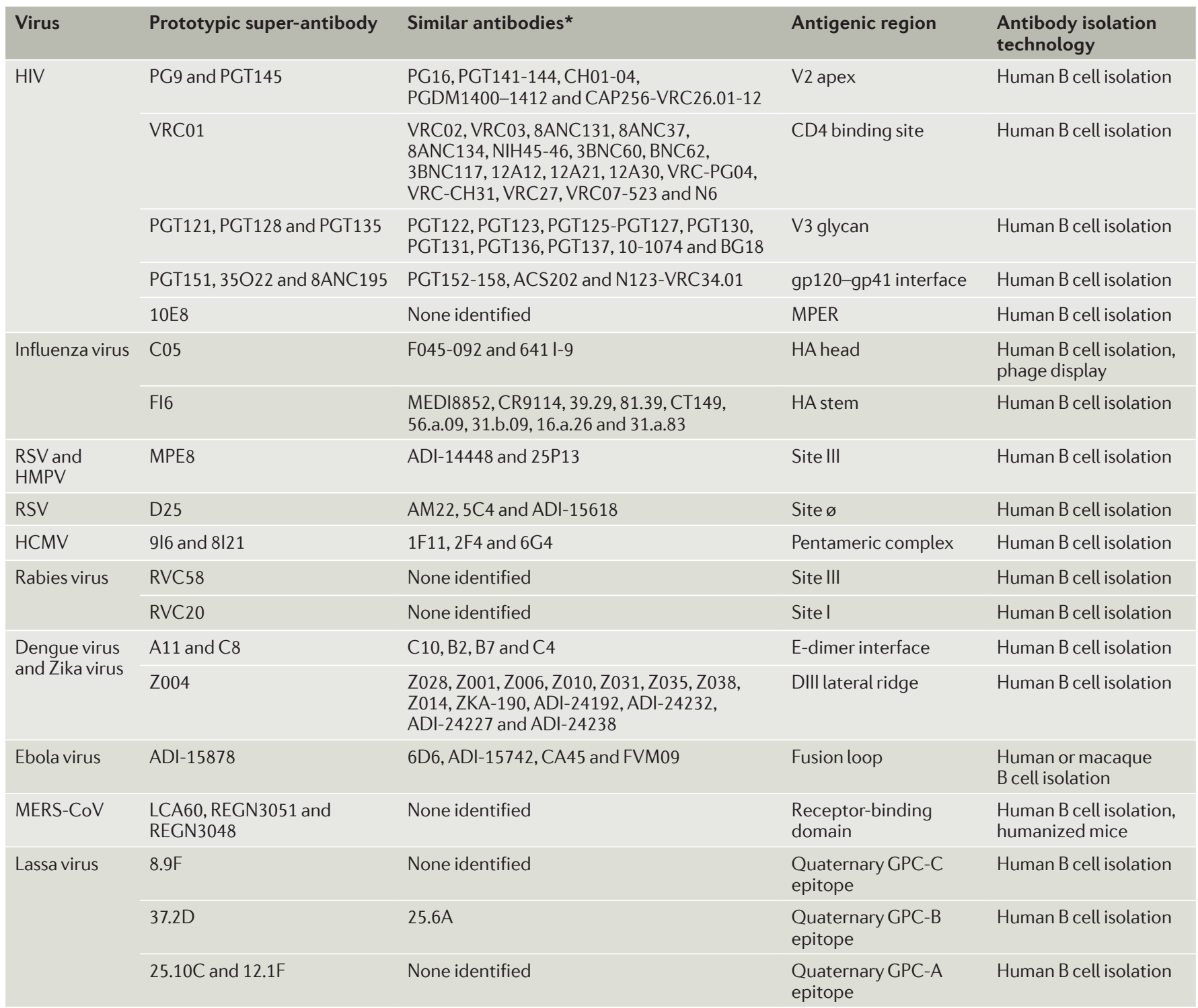

*This list of antibodies is not exhaustive and is caveated by the fact that different neutralization assays can give different results. gp120, envelope glycoprotein gp120; gp41, glycoprotein 41; GPC, glycoprotein complex; HA, haemagglutinin; HCMV, human cytomegalovirus; HMPV, human metapneumovirus; MERS-CoV, Middle East respiratory syndrome coronavirus; MPER, membrane-proximal external region; RSV, respiratory syncytial virus.

One of the advantages of the plasmablast approach is that antigen baiting is not required for B cell sorting, thereby allowing for the isolation of antibodies that target epitopes that are poorly presented on recombinant antigens. For example, in the case of dengue virus, potent bnAbs targeting E-dimer-dependent epitopes were isolated using this approach ${ }^{72}$. However, it is important to emphasize that the ability to isolate super-antibodies using this method will depend on several factors. First, during a primary infection, the ASC population will be mainly composed of activated, low-affinity naive B cells (rather than affinity-matured memory B cells), making the possibility of identifying super-antibodies extremely unlikely. Second, in the context of a booster vaccination or secondary infection with an antigenically similar virus, most of the plasmablast response will be directed against immunodominant epitopes, which in many cases are not targeted by effective neutralizing antibodies. In such cases, exhaustive cloning, production and characterization of the plasmablast-derived mAbs would likely be required to identify rare super-antibodies. By contrast, secondary infection with an antigenically related but sufficiently divergent virus can drive the preferential expansion of B cells that target highly conserved epitopes, as exemplified by the unusually high frequency of bnAbs induced in donors who were infected with the novel H1N1 influenza virus in 2009 (REFS 29,75). In principle, one could use this type of approach for the generation of super-antibodies in humanized mice or other animal models by using suitably designed immunogens and immunization regimens. 

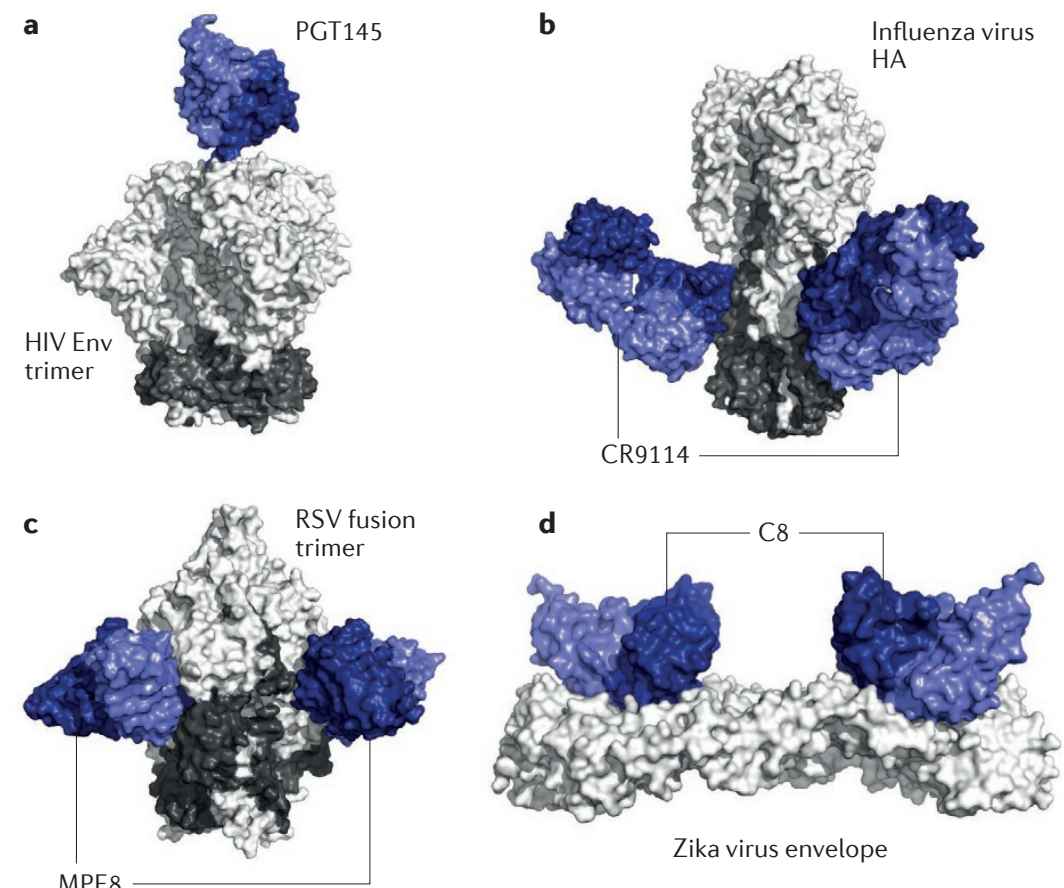

Zika virus envelope

Figure 2 | Structures of super-antibodies bound to their target antigens. a | Cryoelectron microscopy structure of the broadly neutralizing anti-HIV-1 antibody PGT145 in complex with a recombinant HIV envelope (Env) trimer. PGT145 binds to a glycan-dependent quaternary epitope at the trimer apex ${ }^{152}$. b $\mid$ Crystal structure of the influenza virus group 1 and group 2 neutralizing antibody CR9114 in complex with influenza virus haemagglutinin (HA). CR9114 recognizes a highly conserved epitope in the HA stem ${ }^{154,155}$. c | Crystal structure of the respiratory syncytial virus (RSV) and human metapneumovirus cross-neutralizing antibody MPE8 in complex with a stabilized RSV prefusion fusion glycoprotein trimer. d | Crystal structure of the Zika virus and dengue virus cross-neutralizing antibody C8 in complex with a soluble Zika virus Env ectodomain. C8 targets a quaternary epitope that bridges two Env protein subunits. Part a is adapted from REF. 151, CC-BY-4.0. Part $\mathbf{b}$ is adapted with permission from REF. 153, AAAS. Part $\mathbf{c}$ is adapted from REF. 156, Macmillan Publishers Limited. Part d is adapted from REF. 85, Macmillan Publishers Limited.

Transchromosomal cows Cows that have been genetically modified to incorporate human

chromosomes so that upon immunization they generate human antibodies.

\section{Rapid response platforms for emerging viruses}

Over the past two decades, humanity has faced a newly emerging, or re-emerging, viral threat almost every year, including severe acute respiratory syndrome coronavirus (SARS), West Nile virus, pandemic influenza virus, Ebola virus, MERS-CoV and Zika virus. Because of their comparatively fast path to approval and generally favourable safety profiles, $\mathrm{mAb}$ therapies represent a promising alternative to vaccines and small-molecule drugs for the treatment and prevention of emerging viral threats. Recently, several laboratories have demonstrated the feasibility of identifying, characterizing and scaling-up production of highly potent $\mathrm{mAbs}$ in remarkably short time frames.

In response to the 2014-2015 MERS-CoV outbreak, two different groups illustrated the power of their $\mathrm{mAb}$ discovery platforms by isolating highly potent MERSspecific $\mathrm{mAbs}$, producing the $\mathrm{mAbs}$ in gram quantities and testing the lead mAbs in animal models at an unprecedented speed ${ }^{53,77}$. In one of these studies, a single highly potent MERS-CoV-neutralizing $\mathrm{mAb}$ was identified from the memory $\mathrm{B}$ cells of a convalescent donor through the use of a high-throughput functional screening approach ${ }^{53}$. This $\mathrm{mAb}$, called LCA60, showed protection both before and after exposure in a mouse model of MERS-CoV infection. Importantly, this process took the authors only 4 months from the initial B cell screening to the development of a stable cell line that produces the neutralizing $\mathrm{mAb}$ at $5 \mathrm{~g} \mathrm{l}^{-1}$. In the second study, human immunoglobulin transgenic mice were immunized with the MERS-CoV spike protein and then used to generate a panel of potent MERS-CoV-specific neutralizing $\mathrm{mAbs}$ within several weeks ${ }^{77}$. The authors also quickly generated a humanized mouse model of MERS-CoV infection, which was used to demonstrate the therapeutic efficacy of their mAbs.

In a third study, vaccination of transchromosomal cows engineered to produce fully human IgG molecules with MERS-CoV was shown to yield high serum titres of MERS-CoV-specific neutralizing antibodies ${ }^{78}$. Importantly, administration of the purified polyclonal transchromosomal bovine human IgG to mice either 12 hours before or 24 and 48 hours after MERS-CoV infection resulted in a significant reduction in viral lung titres. Transchromosomal bovines have also been used to rapidly generate polyclonal neutralizing antibodies to Hanta virus, Venezuelan equine encephalitis virus and Ebola virus ${ }^{79-81}$, demonstrating the feasibility of using this platform to rapidly generate therapeutics to combat emerging viral threats. The antibodies arising from transchromosomal cows are polyclonal to date, but there is potential for $\mathrm{mAb}$ isolation.

Between 2015 and 2016, several groups responded to the 2014-2015 Ebola virus outbreak by swiftly generating highly potent Ebola virus GP-specific neutralizing $\mathrm{mAbs}$ from the memory $\mathrm{B}$ cells of convalescent donors ${ }^{54-56,64,66}$. Many of these mAbs showed potent therapeutic efficacy against either Ebola or Bundibugyo virus after exposure in animal models and a subset showed protective efficacy against multiple Ebola virus strains $s^{54,55,64,66}$. Similarly, several groups have recently reported on the isolation of potent Zika-virus-specific neutralizing $m A b s$ from human donors ${ }^{14,44,82,83}$. Notably, one of these neutralizing mAbs, called ZIKV-117, showed protection against Zika virus after exposure in both pregnant and nonpregnant mice ${ }^{82}$.

In certain cases, the availability of super-antibodies that target highly conserved epitopes may shorten timelines further by bypassing the need for mAb discovery. For example, it was recently shown that a subset of dengue-virus-specific $\mathrm{mAbs}$ potently cross-neutralizes Zika virus ${ }^{84-86}$. These bnAbs - perhaps carrying Fc mutations that ablate $\mathrm{Fc}$ receptor binding to avoid the potential for antibody-dependent enhancement ${ }^{14}-$ could immediately be used for prophylaxis for pregnant women living in Zika-virus-endemic regions. Notably, cocktails of super-antibodies targeting different epitopes, or bispecific or trispecific super-antibody constructs, will likely be required to prevent neutralization escape ${ }^{87-93}$.

\section{Antibodies in prophylaxis and therapy}

Antibodies can function against viruses by several mechanisms, primarily divided into activities against 
Antibody-dependent cellular cytotoxicity (ADCC). A mechanism by which Fc receptor-bearing effector cells such as natural killer (NK) cells recognize and kill antibody-coated target cells, such as virus-infected cells. The Fc portions of the coating antibodies interact with an $\mathrm{Fc}$ receptor (for example, Fc $\gamma R$ RIII; which is expressed by NK cells), thereby initiating a signalling cascade that results in the release of cytotoxic granules (containing perforin and granzyme B) from the effector cell, which lead to cell death of the antibody-coated cell.

\section{Complement-dependent} cytotoxicity

A mechanism of

antibody-mediated immunity whereby the association of an antibody on a target cell surface leads to binding of the complement component $\mathrm{Clq}$ and triggering of the classical complement cascade. The cascade leads to elimination of target cells by a number of mechanisms, including the formation of the membrane attack complex, the cytolytic end product of the

complement cascade.

Hyperimmune globulins Antibody preparations generated from plasma of donors with high titres of an antibody against a specific pathogen or antigen.

Hyperimmune globulins are available against rabies virus, hepatitis B virus and varicella zoster virus, among other viruses. free virus particles and activities against infected cells. Neutralization, measured in vitro as the ability of an antibody to prevent viral entry into target cells without a requirement for involvement of any other agents, is an activity against free virions that has been most correlated with protection in vivo. Activities against infected cells generally depend on Fc effector functions and involve host effector cells. They include antibody-dependent cellular cytotoxicity (ADCC), complement-dependent cytotoxicity and antibody-dependent cellular phagocytosis (ADCP). It is presumed that these activities are likely to be important in antibody-based therapy. Because neutralization frequently correlates with the ability to bind to native structures on the virion surface, it can give some indication of the ability of antibodies to mediate effector activities such as ADCC and ADCP. The potency of super-antibodies is then often estimated from neutralization measurements, although ultimately it is of course in vivo activity that is crucial.

Prophylaxis. Vaccination is the most effective and lowcost method of preventing viral disease. However, the development of effective vaccines against many important viral pathogens - including HIV, RSV, hepatitis C virus, dengue virus and HCMV - has been met with limited success. Furthermore, vaccine development is a long complex process, often lasting 10-15 years, making immunization an impractical means of protecting individuals from newly emerging viral threats unless pan-virus family vaccines can be developed. For example, if antibodies can be identified that potently neutralize existing strains of Ebola virus, or even Ebola and Marburg filoviruses, then one could anticipate that a vaccine templated from the antibodies would also be effective against emerging strains of Ebola virus. However, at the current time, passive antibody prophylaxis represents a promising alternative to vaccination for a number of viral infections.

Currently, three purified polyclonal hyperimmune globulins derived from human donors immune to hepatitis B virus, HCMV or varicella zoster virus are on the market for the prevention of serious diseases associated with these viruses. A rabies-virus-specific immune globulin, combined with vaccination, is also available for prophylaxis after exposure. In 1998, palivizumab - a humanized $\mathrm{mAb}$ that targets the RSV F protein became the first antiviral $\mathrm{mAb}$ approved by the US Food and Drug Administration. Palivizumab soon replaced the RSV hyperimmune globulin (RespiGam) for the prevention of severe RSV-associated disease in highrisk infants. However, although palivizumab is more specific and 50-100 times more potent than RespiGam, the cost associated with the required dosing makes its use impractical for all infants ${ }^{94}$. A second-generation RSV-specific $\mathrm{mAb}$, which shows up to 50 times greater neutralization potency than palivizumab and contains substitutions in the Fc domain that extend its serum half-life, is currently in phase II clinical trials for the prevention of severe RSV-associated disease in all infants ${ }^{95}$ (TABLE 2).
Although palivizumab is the only commercially available $\mathrm{mAb}$ for the prevention of a viral disease, there are multiple antiviral $\mathrm{mAbs}$ in preclinical and clinical development that have shown efficacy prior to exposure in animal models. For example, the potent MERSCoV-specific mAbs described above were shown to prophylactically protect humanized mice against MERSassociated disease. Similarly, mAbs to chikungunya virus, influenza virus, HIV and Ebola virus have shown potent prophylactic efficacy in animal models $s^{9,85,96-102}$. Recently, a broadly neutralizing anti-Zika virus $\mathrm{mAb}$ (ZIKV-117) was shown to protect against maternal-fetal transmission in a mouse model of Zika virus infection ${ }^{82}$. If this observation translates to humans, prophylaxis with ZIKV-117 or similar neutralizing mAbs may be a promising means of protecting at-risk pregnant women against Zika virus infection and fetal transmission.

In the case of HIV, multiple studies have shown that passively administered neutralizing mAbs provide protection against intravenous, vaginal, rectal and oral challenge in nonhuman primate and mouse models ${ }^{99-101,103-106}$. A large ongoing study (the AntibodyMediated Prevention (AMP) study will assess the ability of the VRC01 mAb specific for the CD4 binding site to decrease the risk of HIV acquisition in humans. Although animal studies have provided proof of principle that a vaccine capable of inducing sufficient titres of bnAbs could prevent the establishment of HIV infection in humans, and the AMP study will investigate this directly, the design of immunogens that efficiently elicit these rare antibodies remains a formidable challenge.

To bypass the challenges associated with active vaccination against HIV, a number of groups have proposed alternative strategies on the basis of vector-mediated antibody gene transfer to express bnAbs in vivo ${ }^{107}$. Unlike traditional passive immunization, which would require long-term repeated treatment with bnAbs, vectored immunoprophylaxis involves only a single injection and enables continuous and sustained delivery of antibodies. In 2009, pioneering work demonstrated that vector-mediated delivery of antibody-like molecules can provide vaccine-like protection against simian immunodeficiency virus (SIV) challenge in nonhuman primate models ${ }^{108}$. Subsequent studies have shown that vectored immunoprophylaxis is also compatible with full-length IgG molecules and CD4-like molecules ${ }^{109-111}$. If the preclinical results in mice and macaques translate to humans, vectored antibody gene delivery strategies could provide an alternative form of prophylaxis against HIV and other challenging vaccine targets, such as hepatitis $C$ virus, pandemic influenza virus and malaria. Recently, nonviral vector nucleic acid delivery technologies have also been developed to obviate the potential safety issues associated with viral vector-mediated delivery, such as long-term persistence and potential viral DNA integration into the host genome $e^{112-117}$. In a recent study, it was shown that the administration of lipid-encapsulated nucleoside-modified mRNAs encoding the heavychain and light-chain genes of the broadly neutralizing HIV-1-specific antibody VRC01 to humanized 
Table 2 | Antiviral monoclonal antibodies in clinical development

\begin{tabular}{|c|c|c|c|c|c|c|}
\hline Antibody & Virus & $\begin{array}{l}\text { Antibody isolation } \\
\text { technology }\end{array}$ & Target & $\begin{array}{l}\text { Stage of } \\
\text { development }\end{array}$ & Manufacturer & Indication \\
\hline PRO 140 & HIV & $\begin{array}{l}\text { Immunization and } \\
\text { humanization }\end{array}$ & CCR5 & Phase III & $\begin{array}{l}\text { Progenics } \\
\text { Pharmaceuticals }\end{array}$ & Treatment of HIV-1 infection \\
\hline UB 421 & HIV & $\begin{array}{l}\text { Immunization and } \\
\text { humanization }\end{array}$ & CD4 & Phase II & United Biomedical & Treatment of HIV-1 infection \\
\hline VRC01-LS & HIV & Human B cell isolation & HIV gp120 & Phase I & $\begin{array}{l}\text { National Institute of } \\
\text { Allergy and Infectious } \\
\text { Diseases }\end{array}$ & $\begin{array}{l}\text { Prevention of HIV-1 } \\
\text { infection }\end{array}$ \\
\hline 3BNC117-LS & HIV & Human B cell isolation & HIV gp120 & Phase I & Rockefeller University & Treatment of HIV-1 infection \\
\hline $\begin{array}{l}\text { 10-1074 and } \\
\text { 3BNC117 }\end{array}$ & HIV & Human B cell isolation & HIV gp120 & Phase I & Rockefeller University & Treatment of HIV-1 infection \\
\hline PGT121 & HIV & Human $B$ cell isolation & HIV gp120 & Phase I & $\begin{array}{l}\text { International AIDS } \\
\text { Vaccine Initiative }\end{array}$ & $\begin{array}{l}\text { Treatment and prevention of } \\
\text { HIV-1 infection }\end{array}$ \\
\hline $\begin{array}{l}\text { PGDM1400 } \\
\text { and PGT121 }\end{array}$ & HIV & Human B cell isolation & HIV gp120 & Phase I & $\begin{array}{l}\text { International AIDS } \\
\text { Vaccine Initiative }\end{array}$ & $\begin{array}{l}\text { Treatment and prevention of } \\
\text { HIV-1 infection }\end{array}$ \\
\hline MB 66 & $\begin{array}{l}\text { HIV and } \\
\text { HSV }\end{array}$ & Human B cell isolation & $\begin{array}{l}\text { HIV gp120 } \\
\text { and HSV } \\
\text { glycoprotein D }\end{array}$ & Phase I & $\begin{array}{l}\text { Mapp } \\
\text { Biopharmaceutical }\end{array}$ & $\begin{array}{l}\text { Prevention of HIV-1 and HSV } \\
\text { sexual transmission }\end{array}$ \\
\hline VIS 410 & $\begin{array}{l}\text { Influenza } \\
\text { virus }\end{array}$ & Unknown & Influenza virus HA & Phase II & Visterra & $\begin{array}{l}\text { Treatment and prevention of } \\
\text { influenza A virus infection }\end{array}$ \\
\hline CR8020 & $\begin{array}{l}\text { Influenza } \\
\text { virus }\end{array}$ & Human B cell isolation & Influenza virus HA & Phase II & Crucell & $\begin{array}{l}\text { Treatment and prevention of } \\
\text { influenza A virus infection }\end{array}$ \\
\hline RG 6024 & $\begin{array}{l}\text { Influenza } \\
\text { virus }\end{array}$ & Human B cell isolation & Influenza virus HA & Phase I & Genentech & $\begin{array}{l}\text { Treatment of influenza B } \\
\text { virus infection }\end{array}$ \\
\hline MEDI 8852 & $\begin{array}{l}\text { Influenza } \\
\text { virus }\end{array}$ & Human B cell isolation & Influenza virus HA & Phase II & Medlmmune & $\begin{array}{l}\text { Treatment of influenza A } \\
\text { virus infection }\end{array}$ \\
\hline TCN 032 & $\begin{array}{l}\text { Influenza } \\
\text { virus }\end{array}$ & Human B cell isolation & $\begin{array}{l}\text { Influenza virus } \\
\text { M2e protein }\end{array}$ & Phase II & $\begin{array}{l}\text { Theraclone Sciences; } \\
\text { Zenyaku Kogyo }\end{array}$ & $\begin{array}{l}\text { Treatment of influenza A } \\
\text { virus infection }\end{array}$ \\
\hline m 102.4 & $\begin{array}{l}\text { Nipah and } \\
\text { Hendra } \\
\text { virus }\end{array}$ & Phage display & $\begin{array}{l}\text { Viral Env } \\
\text { glycoprotein G }\end{array}$ & Phase I & $\begin{array}{l}\text { Profectus Biosciences, } \\
\text { Inc. }\end{array}$ & $\begin{array}{l}\text { Prevention and treatment } \\
\text { of Nipah and Hendra virus } \\
\text { infections }\end{array}$ \\
\hline Rabimabs & Rabies virus & Immunization & Viral Env G protein & Phase I and II & $\begin{array}{l}\text { World Health } \\
\text { Organization; Zydus } \\
\text { Cadila }\end{array}$ & $\begin{array}{l}\text { Treatment and prevention } \\
\text { of rabies }\end{array}$ \\
\hline RAB-1 & Rabies virus & Humanized mice & Viral Env G protein & Approved & $\begin{array}{l}\text { Serum Institute of } \\
\text { India; MassBiologics }\end{array}$ & $\begin{array}{l}\text { Prophylaxis after exposure } \\
\text { to rabies }\end{array}$ \\
\hline Foravirumab & Rabies virus & $\begin{array}{l}\text { Phage display, human } \\
\text { B cell isolation }\end{array}$ & Viral Env G protein & $\begin{array}{l}\text { Phase II and } \\
\text { III }\end{array}$ & Crucell; Sanofi Pasteur & $\begin{array}{l}\text { Prophylaxis after exposure } \\
\text { to rabies }\end{array}$ \\
\hline Palivizumab & RSV & $\begin{array}{l}\text { Immunization and } \\
\text { humanization }\end{array}$ & $\begin{array}{l}\text { Viral fusion } \\
\text { protein }\end{array}$ & Approved & Medlmmune & $\begin{array}{l}\text { Prophylaxis in high-risk } \\
\text { infants }\end{array}$ \\
\hline MEDI 8897 & RSV & Human B cell isolation & Viral fusion protein & Phase II & Medlmmune & Prophylaxis in all infants \\
\hline
\end{tabular}

CCR5, CC-chemokine receptor 5; E2, envelope glycoprotein (HCV); Env, envelope; gp120, envelope glycoprotein gp120; HA, haemagglutinin; HCV, hepatitis C virus; HSV, herpes simplex virus; M2e, matrix protein 2 (influenza virus); RSV, respiratory syncytial virus. 
mice resulted in high serum antibody concentrations and protection against intravenous HIV-1 challenge ${ }^{114}$.

Similar proof-of-concept studies have also been performed using synthetic DNA plasmid-mediated antibody gene transfer ${ }^{112,113}$. In one such study, synthetic DNA plasmids encoding cross-neutralizing anti-dengue virus antibodies were delivered to mice by electroporation and resulted in biologically relevant levels of serum antibody ${ }^{112}$. Importantly, a single intramuscular injection of plasmid DNA conferred protection against severe dengue disease in a mouse model. Although several technical challenges remain to be addressed, such as enhancing in vivo antibody expression levels and reducing the potential for immunogenicity, these studies demonstrate the feasibility of utilizing plasmid DNA and modified mRNA-based antibody delivery technologies for passive immunotherapy.

Therapy. Conventional wisdom says that antibodies are effective if present before or shortly after viral exposure, but their effectiveness declines markedly once infection is established. For example, the antiRSV antibody palivizumab is effective in the clinic prophylactically but not therapeutically ${ }^{118}$. However, there are indications that the dogma may be challenged by super-antibodies. An example is the ability of a new generation of bnAbs against HIV to strongly impact ongoing infection in animal models $s^{87,119,120}$ in which an earlier generation of less-potent mAbs had very limited effects ${ }^{121}$. This ability likely reflects the increased neutralization potency of the superantibodies as well as the increased breadth of neutralization that may restrict virus escape pathways ${ }^{119}$. A number of super-antibodies are now being evaluated in humans for their activities against established HIV infection ${ }^{122-126}$ (TABLE 2). Initial results are interesting, providing for example an indication of enhanced immune responses following bnAb administration ${ }^{127}$. The emerging results will be followed closely, including in the context of combining bnAbs with drugs and other antiviral agents to attempt HIV cure.

For other viruses, clear evidence of a strong therapeutic effect for super-antibodies has not been gathered yet. Several cases such as antibody treatment of rabies virus and Junin virus infections ${ }^{43,128}$ are probably better interpreted as prophylaxis after exposure rather than therapy for an established infection. Two promising examples of possible therapy are the successful treatment of Ebola-virus-infected or Lassa-virusinfected monkeys with mAbs once symptoms have appeared ${ }^{89,129}$. Unfortunately, no definitive evidence of the effectiveness of mAbs in Ebola-symptomatic or Lassa-symptomatic humans yet exists.

Camelid-derived single-domain antibodies (sdAbs), which contain a single heavy-chain variable domain, represent a promising new class of antibody-based therapeutics for RSV and other viruses that cause lower respiratory tract infections ${ }^{130-133}$. Because of their small size and high solubility and stability, sdAbs can be rapidly delivered to the site of infection via inhalation. Notably, a neutralizing anti-RSV sdAb (ALX-0171) that targets an epitope overlapping that bound by palivizumab recently showed a trend towards a therapeutic effect in a phase I and IIa clinical trial based on reduced viral loads and clinical symptoms in hospitalized RSVinfected infants. Prefusion F-protein-specific sdAbs that show up to 180,000 times greater neutralization potency than ALX-0171 have recently been identified and may offer even greater therapeutic benefit ${ }^{133}$.

\section{Practical considerations}

Intuitively, the enhanced potency of super-antibodies is immediately recognized as beneficial in antibody prophylaxis and therapy. However, there are also a number of additional effects from this enhanced potency that may not be instantly appreciated and that can be further strengthened by antibody engineering. For example, enhanced potency means that less antibody needs to be used, and this can enable easierto-develop, low-concentration subcutaneous administration rather than the use of more-difficult-to-develop, high-concentration subcutaneously administered formulations or less-convenient (low-concentration) intravenous administration. Enhanced potency also means that the lifetime of an effective antibody following administration is extended, thereby requiring fewer administrations to maintain a useful protective or therapeutic effect. Antibody engineering can also extend its half-life considerably ${ }^{95,134-139}$ so that for the most potent super-antibodies, one could envisage requiring administrations perhaps only every 3-6 months for effectiveness. Antibody engineering can also deliver greater effectiveness through enhanced Fc effector function $^{140,141}$.

\section{Conclusions}

The deployment of antibodies as antiviral agents has progressed through a number of stages over the years, corresponding to increasing levels of potency of the reagent administered. Passive immunotherapy began with immune serum over a century ago, then progressed to polyclonal antibodies, then mAbs and now into highly potent human mAbs dubbed superantibodies. Thanks to research that has been primarily carried out in the field of cancer research, technologies have been developed to endow these super-antibodies with enhanced in vivo function.

Will super-antibodies change the landscape of antiviral prophylaxis and therapy? The answer to this question will depend on a number of factors: first, the rapidity of development of antiviral vaccines (vaccines will likely remain the least expensive and most effective antiviral measure, but some viruses such as HIV present a large challenge to vaccine development); second, the effective cost of antibody treatment, which incorporates not only manufacturing cost but also the durability of the administered antibody and the route of administration; and third, the success of antibodies in the treatment of established viral infections. Particularly in the therapeutic setting, the answers can only be obtained with clinical trials using the best super-antibodies available. 
1. Hey, A. History and practice: antibodies in infectious diseases. Microbiol. Spectr. http://dx.doi.org/10.1128/ microbiolspec.AID-0026-2014 (2015).

2. Graham, B. S. \& Ambrosino, D. M. History of passive antibody administration for prevention and treatment of infectious diseases. Curr. Opin. HIV AIDS 10 129-134 (2015)

This article is an excellent account of the history of passive antibody administration.

3. Sparrow, E., Friede, M., Sheikh, M. \& Torvaldsen, S. Therapeutic antibodies for infectious diseases. Bull. World Health Organ. 95, 235-237 (2017).

4. Berry, J. D. \& Gaudet, R. G. Antibodies in infectious diseases: polyclonals, monoclonals and niche biotechnology. N. Biotechnol. 28, 489-501 (2011).

5. Saylor, C., Dadachova, E. \& Casadevall, A. Monoclonal antibody-based therapies for microbial diseases. Vaccine 27 (Suppl. 6), G38-G46 (2009).

6. Wilson, P. C. \& Andrews, S. F. Tools to therapeutically harness the human antibody response. Nat. Rev. Immunol. 12, 709-719 (2012).

7. Burton, D. R. What are the most powerful immunogen design vaccine strategies? Reverse vaccinology 2.0 shows great promise. Cold Spring Harb. Perspect. Biol. 9, a030262 (2017).

8. Chen, Z. et al. Cross-neutralizing human anti-poliovirus antibodies bind the recognition site for cellular receptor. Proc. Natl Acad. Sci. USA 110, 20242-20247 (2013)

9. Smith S. A et al. Isolation and characterization of broad and ultrapotent human monoclonal antibodies with therapeutic activity against Chikungunya virus. Cell Host Microbe 18, 86-95 (2015)

10. Tahara, M. et al. Functional and structural characterization of neutralizing epitopes of measles virus hemagglutinin protein. J. Virol. 87, 666-675 (2013).

11. Gilman, M. S. et al. Rapid profiling of RSV antibody repertoires from the memory $B$ cells of naturally infected adult donors. Sci. Immunol. 1, eaaj 1879 (2016).

12. Corti, D. et al. Cross-neutralization of four paramyxoviruses by a human monoclonal antibody. Nature 501, 439-443 (2013)

This paper is one of the first descriptions of an mAb with pan-virus-type neutralizing ability.

13. Macagno, A. et al. Isolation of human monoclona antibodies that potently neutralize human cytomegalovirus infection by targeting different epitopes on the gH/gL/UL128-131 A complex. J. Virol. 84, 1005-1013 (2010)

14. Stettler, K. et al. Specificity, cross-reactivity, and function of antibodies elicited by Zika virus infection. Science 353, 823-826 (2016).

15. Sommerstein, R. et al. Arenavirus glycan shield promotes neutralizing antibody evasion and protracted infection. PLoS Pathog. 11, e 1005276 (2015).

16. Sather, D. N. et al. Factors associated with the development of cross-reactive neutralizing antibodies during human immunodeficiency virus type 1 infection. J. Virol. 83, 757-769 (2009).

17. Gray, E. S. et al. The neutralization breadth of HIV-1 develops incrementally over four years and is associated with $\mathrm{CD} 4^{+} \mathrm{T}$ cell decline and high viral load during acute infection. J. Virol. 85, 4828-4840 (2011).

18. Doria-Rose, N. A. et al. Breadth of human immunodeficiency virus-specific neutralizing activity in sera: clustering analysis and association with clinical variables. J. Virol 84, 1631-1636 (2010).

19. Simek, M. D. et al. Human immunodeficiency virus type 1 elite neutralizers: individuals with broad and potent neutralizing activity identified by using a highthroughput neutralization assay together with an analytical selection algorithm. J. Virol. 83

7337-7348 (2009).

This study describes the assembly and use of a large cohort of HIV-infected individuals with broad neutralizing sera as the starting point for super-antibody generation.

20. Jahrling, P. B., Frame, J. D., Rhoderick, J. B. \& Monson, M. H. Endemic Lassa fever in Liberia. IV. Selection of optimally effective plasma for treatmen by passive immunization. Trans. R. Soc. Trop. Med. Hyg. 79, 380-384 (1985).

21. Andrews, S. F. et al. Immune history profoundly affects broadly protective B cell responses to influenza. Sci. Transl Med. 7, 316 ra192 (2015)

22. Kwong, P. D. \& Mascola, J. R. Human antibodies that neutralize HIV-1: identification, structures, and B cell ontogenies. Immunity 37, 412-425 (2012).
23. Burton, D. R. \& Mascola, J. R. Antibody responses to envelope glycoproteins in HIV-1 infection. Nat. Immunol. 16, 571-576 (2015)

24. Kwong, P. D., Mascola, J. R. \& Nabel, G. J. Broadly neutralizing antibodies and the search for an HIVvaccine: the end of the beginning. Nat. Rev. Immunol. 13, 693-701 (2013)

25. Burton, D. R. \& Hangartner, L. Broadly neutralizing antibodies to HIV and their role in vaccine design. Annu. Rev. Immunol. 34, 635-659 (2016).

26. West, A. P. Jr et al. Structural insights on the role of antibodies in HIV-1 vaccine and therapy. Cell 156 633-648 (2014).

27. Corti, D. \& Lanzavecchia, A. Broadly neutralizing antiviral antibodies. Annu. Rev. Immunol. 31, 705-742 (2013).

This article is a comprehensive review of bnAbs against multiple viruses.

28. Li, Y. et al. Immune history shapes specificity of pandemic $\mathrm{H} 1 \mathrm{~N} 1$ influenza antibody responses. J. Exp. Med. 210, 1493-1500 (2013)

29. Li, G. M. et al. Pandemic H1N1 influenza vaccine induces a recall response in humans that favors broadly cross-reactive memory B cells. Proc. Natl Acad. Sci. USA 109, 9047-9052 (2012).

30. Joyce, M. G. et al. Vaccine-induced antibodies that neutralize group 1 and group 2 influenza A viruses. Cell 166, 609-623 (2016)

31. Andrews, S. F. et al. Preferential induction of crossgroup influenza A hemagglutinin stem-specific memory B cells after $\mathrm{H} 7 \mathrm{~N} 9$ immunization in humans. $\mathrm{SC}$. Immunol. 2, eaan2676 (2017).

32. Lee, J. E. et al. Structure of the Ebola virus glycoprotein bound to an antibody from a human survivor. Nature 454, 177-182 (2008).

33. Burton, D. R., Poignard, P., Stanfield, R. L. \& Wilson, I. A. Broadly neutralizing antibodies present new prospects to counter highly antigenically diverse viruses. Science 337, 183-186 (2012).

34. Burton, D. R. A vaccine for HIV type 1: the antibody perspective. Proc. Natl Acad. Sci. USA 94 10018-10023 (1997)

35. Li, Y. et al. Broad HIV-1 neutralization mediated by CD4-binding site antibodies. Nat. Med. 13 , 1032-1034 (2007).

36. Medina-Ramirez, M. et al. Broadly cross-neutralizing antibodies in HIV-1 patients with undetectable viremia. J. Virol. 85, 5804-5813 (2011)

37. Walker, L. M. et al. Broad and potent neutralizing antibodies from an African donor reveal a new HIV- 1 vaccine target. Science 326, 285-289 (2009). This article presents the isolation of the first of a new generation of HIV bnAbs and one of the first super-antibodies.

38. Falkowska, E. et al. PGV04, an HIV-1 gp 120 CD4 binding site antibody, is broad and potent in neutralization but does not induce conformationa changes characteristic of CD4. J. Virol. $\mathbf{8 6}$, 4394-4403 (2012)

39. Walker $\mathrm{M}$ et al Broad neutralization coverage of HIV by multiple highly potent antibodies. Nature 477 , 466-470 (2011)

40. Sok, D. et al. Recombinant HIV envelope trimer selects for quaternary-dependent antibodies targeting the trimer apex. Proc. Natl Acad. Sci. USA 111, 17624-17629 (2014).

41. Falkowska, E. et al. Broadly neutralizing HIV antibodies define a glycan-dependent epitope on the prefusion conformation of gp41 on cleaved envelope trimers. Immunity 40, 657-668 (2014).

42. Corti, D. et al. A neutralizing antibody selected from plasma cells that binds to group 1 and group 2 influenza A hemagglutinins. Science 333, 850-856 (2011)

This article describes a very broad influenza virus-specific super-antibody of the type that indicates that a universal flu vaccine may be possible.

43. De Benedictis, P et al. Development of broad spectrum human monoclonal antibodies for rabies post-exposure prophylaxis. EMBO Mol. Med. 8 407-421 (2016).

44. Robbiani, D. F. et al. Recurrent potent human neutralizing antibodies to Zika virus in Brazil and Mexico Cell 169, 597-609.e11 (2017).

45. Mestas, J. \& Hughes, C. C. Of mice and not men differences between mouse and human immunology. J. Immunol. 172, 2731-2738 (2004).

46. Bonsignori, M. et al. Analysis of a clonal lineage of HIV-1 envelope V2/V3 conformational epitope-specific broadly neutralizing antibodies and their inferred unmutated common ancestors. J Virol 85, 9998-10009 (2011).

47. Huang, J. et al. Identification of a CD4-binding-site antibody to HIV that evolved near-pan neutralization breadth. Immunity 45, 1108-1121 (2016).

48. Doria-Rose, N. A. et al. Developmental pathway for potent V1V2-directed HIV-neutralizing antibodies. Nature 509, 55-62 (2014).

49. Kwakkenbos, M. J. et al. Generation of stable monoclonal antibody-producing B cell receptorpositive human memory B cells by genetic programming. Nat. Med. 16, 123-128 (2010).

50. Robinson, J. E. et al. Most neutralizing human monoclonal antibodies target novel epitopes requiring both Lassa virus glycoprotein subunits. Nat. Commun. 7, 11544 (2016).

51. McLellan, J. S. et al. Structure of RSV fusion glycoprotein trimer bound to a prefusion-specific neutralizing antibody. Science 340, 1113-1117 (2013)

52. Gilchuk, I. et al. Cross-neutralizing and protective human antibody specificities to poxvirus infections. Cell 167, 684-694.e9 (2016)

53. Corti, D. et al. Prophylactic and postexposure efficacy of a potent human monoclonal antibody against MERS coronavirus. Proc. Natl Acad. Sci. USA 112 10473-10478 (2015).

54. Flyak, A. l. et al. Cross-reactive and potent neutralizing antibody responses in human survivors of natural ebolavirus infection. Cell 164, 392-405 (2016).

55. Corti, D. et al. Protective monotherapy against lethal Ebola virus infection by a potently neutralizing antibody. Science 351, 1339-1342 (2016).

56. Misasi, J. et al. Structural and molecular basis for Ebola virus neutralization by protective human antibodies. Science 351, 1343-1346 (2016).

57. Babcook, J. S., Leslie, K. B., Olsen, O. A. Salmon, R. A. \& Schrader, J. W. A novel strategy for generating monoclonal antibodies from single, isolated lymphocytes producing antibodies of defined specificities. Proc. Natl Acad. Sci. USA 93 7843-7848 (1996)

This article provides the first description of single $B$ cell technology for the isolation of multiple mAbs.

58. Tiller, T. et al. Efficient generation of monoclonal antibodies from single human B cells by single cel RT-PCR and expression vector cloning. J. Immunol. Methods 329, 112-124 (2008).

This article describes the application of single $B$ cell technology to the isolation of human mAbs.

59. Wardemann, H. et al. Predominant autoantibody production by early human B cell precursors. Science 301, 1374-1377 (2003)

60. Wu, X. et al. Rational design of envelope identifies broadly neutralizing human monoclonal antibodies to HIV-1. Science 329, 856-861 (2010) This article presents the isolation of the prototype broadly neutralizing super-antibody to the CD4 binding site, VRC01.

61. Zhou, T et al. Structural basis for broad and potent neutralization of HIV-1 by antibody VRC01. Science 329, 811-817 (2010)

62. Scheid, J. F. et al. Sequence and structural convergence of broad and potent HIV antibodies that mimic CD4 binding. Science 333, 1633-1637 (2011).

63. Wu, X. et al. Focused evolution of HIV-1 neutralizing antibodies revealed by structures and deep sequencing Science 333, 1593-1602 (2011).

64. Bornholdt, Z. A. et al. Isolation of potent neutralizing antibodies from a survivor of the 2014 Ebola virus outbreak. Science 351, 1078-1083 (2016). This article describes the isolation of large numbers of mAbs from an Ebola virus survivor immediately following the outbreak and rapid identification of super-antibodies.

65. Scherer, E. M. et al. Characteristics of memory B cells elicited by a highly efficacious HPV vaccine in subjects with no pre-existing immunity. PLoS Pathog. 10 , e 1004461 (2014).

66. Wec, A. Z. et al. Antibodies from a human survivor define sites of vulnerability for broad protection against ebolaviruses. Cell 169, 878-890.e15 (2017).

67. Sok, D. et al. Rapid elicitation of broadly neutralizing antibodies to HIV by immunization in cows. Nature 548, 108-111 (2017)

This article describes the reliable generation of broadly neutralizing HIV antibodies by simple immunization in cows, suggesting that this animal has special value in super-antibody generation. 
68. Zhao, X. et al. Immunization-elicited broadly protective antibody reveals ebolavirus fusion loop as a site of vulnerability. Cell 169, 891-904.e15 (2017).

69. Stevens, R. H., Macy, E., Morrow, C. \& Saxon, A. Characterization of a circulating subpopulation of spontaneous antitetanus toxoid antibody producing $\mathrm{B}$ cells following in vivo booster immunization. J. Immunol. 122, 2498-2504 (1979).

70. Wrammert, J. et al. Rapid cloning of high-affinity human monoclonal antibodies against influenza virus. Nature 453, 667-671 (2008).

This article provides a description of a plasmablast approach to super-antibody generation.

71. Priyamvada, L. et al. B Cell responses during secondary Dengue virus infection are dominated by highly cross-reactive, memory-derived plasmablasts. J. Virol. 90, 5574-5585 (2016).

72. Dejnirattisai, W. et al. A new class of highly potent, broadly neutralizing antibodies isolated from viremic patients infected with dengue virus. Nat. Immunol. 16 , 170-177 (2015)

73. Nair, N. et al. VP4- and VP7-specific antibodies mediate heterotypic immunity to rotavirus in humans Sci. Transl Med. 9, eaam5434 (2017).

74. Silveira, E. L. et al. Vaccine-induced plasmablast responses in rhesus macaques: phenotypic characterization and a source for generating antigenspecific monoclonal antibodies. J. Immunol. Methods 416, 69-83 (2015).

75. Wrammert, J. et al. Broadly cross-reactive antibodies dominate the human B cell response against 2009 pandemic $\mathrm{H} 1 \mathrm{~N} 1$ influenza virus infection. J. Exp. Med. 208, 181-193 (2011).

76. Rogers, T. F. et al. Zika virus activates de novo and cross-reactive memory B cell responses in dengueexperienced donors. Sci. Immunol. 2, eaan6809 (2017).

77. Pascal, K. E. et al. Pre- and postexposure efficacy of fully human antibodies against Spike protein in novel humanized mouse model of MERS-CoV infection. Proc. Natl Acad. Sci. USA 112, 8738-8743 (2015).

78. Luke, T. et al. Human polyclonal immunoglobulin G from transchromosomic bovines inhibits MERS-CoV in vivo. Sci. Transl Med. 8, 326ra21 (2016).

79. Hooper, J. W. et al. DNA vaccine-derived human IgC produced in transchromosomal bovines protect in lethal models of hantavirus pulmonary syndrome. Sci. Transl Med. 6, 264ra162 (2014).

80. Gardner, C. L. et al. Antibody preparations from human transchromosomic cows exhibit prophylactic and therapeutic efficacy against Venezuelan equine encephalitis virus. J. Virol. 91, e00226-17 (2017).

81. Dye, J. M. et al. Production of potent fully human polyclonal antibodies against Ebola Zaire virus in transchromosomal cattle. Sci. Rep. 6, 24897 (2016)

82. Sapparapu, G. et al. Neutralizing human antibodies prevent Zika virus replication and fetal disease in mice Nature 540, 443-447 (2016).

83. Wang, Q. et al. Molecular determinants of human neutralizing antibodies isolated from a patient infected with Zika virus. Sci. Transl Med. 8, 369ra179 (2016).

84. Priyamvada, L. et al. Human antibody responses after dengue virus infection are highly cross-reactive to Zika virus. Proc. Natl Acad. Sci. USA 113, 7852-7857 (2016).

85. Barba-Spaeth, G. et al. Structural basis of potent Zikadengue virus antibody cross-neutralization. Nature 536, 48-53 (2016).

86. Beltramello, M. et al. The human immune response to Dengue virus is dominated by highly crossreactive antibodies endowed with neutralizing and enhancing activity. Cell Host Microbe 8, 271-283 (2010).

87. Shingai, M. et al. Antibody-mediated immunotherapy of macaques chronically infected with SHIV suppresses viraemia. Nature 503, 277-280 (2013).

88. Prabakaran, M. et al. Combination therapy using chimeric monoclonal antibodies protects mice from lethal $\mathrm{H} 5 \mathrm{~N} 1$ infection and prevents formation of escape mutants. PLoS ONE 4, e5672 (2009).

89. Mire, C. E. et al. Human-monoclonal-antibody therapy protects nonhuman primates against advanced Lassa fever. Nat. Med. 23, 1146-1149 (2017). This study is the first demonstration in nonhuman primates that mAbs can protect against advanced Lassa fever.

90. Magnani, D. M. et al. Neutralizing human monoclona antibodies prevent Zika virus infection in macaques. Sci. Transl Med. 9, eaan8184 (2017).
91. Xu, L. et al. Trispecific broadly neutralizing HIV antibodies mediate potent SHIV protection in macaques. Science 358, 85-90 (2017). This study provides a novel design of antibodies to cope with HIV diversity by incorporating three specificities into a single antibody-like molecule.

92. Julg, B. et al. Protection against a mixed SHIV challenge by a broadly neutralizing antibody cocktail. Sci. Transl Med. 9, eaao4235 (2017).

93. Wang, J. et al. A human bi-specific antibody against Zika virus with high therapeutic potential. Cell 171. 229-241.e15 (2017)

94. [No authors listed.] Palivizumab, a humanized respiratory syncytial virus monoclonal antibody, reduces hospitalization from respiratory syncytial virus infection in high-risk infants. The IMpact-RSV Study Group. Pediatrics 102, 531-537 (1998).

95. Zhu, Q. et al. A highly potent extended half-life antibody as a potential RSV vaccine surrogate for all infants. Sci. Transl Med. 9, eaaj1928 (2017).

This article is a description of an RSV-specific super-antibody that shows about ten times greater in vivo efficacy than palivizumab in cotton rats.

96. Sui, J. et al. Structural and functional bases for broadspectrum neutralization of avian and human influenza A viruses. Nat. Struct. Mol. Biol. 16, 265-273 (2009).

97. Qiu, X. et al. Ebola GP-specific monoclonal antibodies protect mice and guinea pigs from lethal Ebola virus infection. PLoS Negl. Trop. Dis. 6, e1575 (2012).

98. Wilson, J. A et al. Epitopes involved in antibodymediated protection from Ebola virus. Science 287 , 1664-1666 (2000).

99. Mascola, J. R. et al. Protection of Macaques against pathogenic simian/human immunodeficiency virus 89.6PD by passive transfer of neutralizing antibodies. J. Virol. 73, 4009-4018 (1999).

100. Mascola, J. R. et al. Protection of macaques against vaginal transmission of a pathogenic HIV-1/SIV chimeric virus by passive infusion of neutralizing antibodies. Nat. Med. 6, 207-210 (2000).

101. Parren, P. W. et al. Antibody protects macaques against vaginal challenge with a pathogenic R5 simian/ human immunodeficiency virus at serum levels giving complete neutralization in vitro. J. Virol. 75 , 8340-8347 (2001)

102. Paules, C. I. et al. The hemagglutinin A stem antibody MEDI8852 prevents and controls disease and limits transmission of pandemic influenza viruses. J. Infect. Dis. 216, 356-365 (2017).

103. Hessell, A. J. et al. Effective, low-titer antibody protection against low-dose repeated mucosal SHIV challenge in macaques. Nat. Med. 15, 951-954 (2009)

104. Hessell, A. J. et al. Broadly neutralizing human antiHIV antibody $2 \mathrm{G} 12$ is effective in protection against mucosal SHIV challenge even at low serum neutralizing titers. PLoS Pathog. 5, e1000433 (2009)

105. Shingai, M. et al. Passive transfer of modest titers of potent and broadly neutralizing anti-HIV monoclonal antibodies block SHIV infection in macaques. J. Exp. Med. 211, 2061-2074 (2014)

106. Julg, B. et al. Broadly neutralizing antibodies targeting the HIV-1 envelope V2 apex confer protection against a clade C SHIV challenge. Sci. Transl Med. 9, eaal1321 (2017).

107. Deal, C. E. \& Balazs, A. B. Vectored antibody gene delivery for the prevention or treatment of HIV infection. Curr. Opin. HIV AIDS 10, 190-197 (2015).

108. Johnson, P. R. et al. Vector-mediated gene transfer engenders long-lived neutralizing activity and protection against SIV infection in monkeys. Nat. Med. 15, 901-906 (2009).

This article is the initial report of vectored prophylaxis applied in macaques.

109. Gardner, M. R. et al. AAV-expressed eCD4-Ig provides durable protection from multiple SHIV challenges. Nature 519, 87-91 (2015)

The article describes the extreme breadth for an engineered antibody molecule incorporating novel features.

110. Balazs, A. B. et al. Antibody-based protection against HIV infection by vectored immunoprophylaxis. Nature 481, 81-84 (2011).

This is a study developing vectored immunoprophylaxis for HIV.

111. Saunders, K. O. et al. Sustained delivery of a broadly neutralizing antibody in nonhuman primates confers ong-term protection against simian/human mmunodeficiency virus infection. J. Virol. $\mathbf{8 9}$ 5895-5903 (2015).
112. Flingai, S. et al. Protection against dengue disease by synthetic nucleic acid antibody prophylaxis/ immunotherapy. Sci. Rep. 5, 12616 (2015).

113. Muthumani, K. et al. Optimized and enhanced DNA plasmid vector based in vivo construction of a neutralizing anti-HIV-1 envelope glycoprotein Fab. Hum. Vaccines Immunother. 9, 2253-2262 (2013).

114. Pardi, N. et al. Administration of nucleoside-modified mRNA encoding broadly neutralizing antibody protects humanized mice from HIV-1 challenge. Nat. Commun. 8, 14630 (2017).

115. Nault, J. C. et al. Recurrent AAV2-related insertional mutagenesis in human hepatocellular carcinomas. Nat. Genet. 47, 1187-1193 (2015).

116. Gao, G. et al. Erythropoietin gene therapy leads to autoimmune anemia in macaques. Blood 103. 3300-3302 (2004).

117. Tjelle, T. E. et al. Monoclonal antibodies produced by muscle after plasmid injection and electroporation. Mol. Ther. 9, 328-336 (2004).

118. Hu, J. \& Robinson, J. L. Treatment of respiratory syncytial virus with palivizumab: a systematic review. World J. Pediatr. 6, 296-300 (2010).

119. Barouch, D. H. et al. Therapeutic efficacy of potent neutralizing HIV-1-specific monoclonal antibodies in SHIV-infected rhesus monkeys. Nature 503, 224-228 (2013) This study describes a surprisingly effective monotherapy for SHIV infection in macaques.

120. Horwitz, J. A. et al. HIV-1 suppression and durable control by combining single broadly neutralizing antibodies and antiretroviral drugs in humanized mice. Proc. Natl Acad. Sci. USA 110, 16538-16543 (2013).

121. Poignard, P. et al. Neutralizing antibodies have limited effects on the control of established HIV-1 infection in vivo. Immunity 10, 431-438 (1999).

122. Caskey, M. et al. Viraemia suppressed in HIV-1-infected humans by broadly neutralizing antibody 3BNC117. Nature 522, 487-491 (2015). This article describes the first use of a super-antibody in HIV infection in humans.

123. Scheid, J. F. et al. HIV-1 antibody 3BNC117 suppresses viral rebound in humans during treatment interruption. Nature 535, 556-560 (2016)

124. Caskey, M. et al. Antibody 10-1074 suppresses viremia in HIV-1-infected individuals. Nat. Med. 23 185-191 (2017).

125. Lynch, R. M. et al. Virologic effects of broadly neutralizing antibody VRC01 administration during chronic HIV-1 infection. Sci. Transl Med. 7, 319 ra206 (2015).

126. Bar, K. J. et al. Effect of HIV antibody VRC01 on viral rebound after treatment interruption. N. Engl. J. Med. 375, 2037-2050 (2016)

127. Schoofs, T. et al. HIV-1 therapy with monoclonal antibody 3BNC 117 elicits host immune responses against HIV-1. Science 352, 997-1001 (2016). This article describes how super-antibody HIV therapy appears to enhance host immune responses in general.

128. Zeitlin, L. et al. Monoclonal antibody therapy for Junin virus infection. Proc. Natl Acad. Sci. USA 113, 4458-4463 (2016).

129. Qiu, X. et al. Reversion of advanced Ebola virus disease in nonhuman primates with ZMapp. Nature 514, 47-53 (2014)

This study is the first demonstration of successful antibody therapy against established Ebola virus disease in nonhuman primates.

130. Van Heeke, G. et al. Nanobodies ${ }^{\circledR}$ as inhaled biotherapeutics for lung diseases. Pharmacol. Ther 169, 47-56 (2017)

131. Schepens, B. et al. Nanobodies ${ }^{\circledR}$ specific for respiratory syncytial virus fusion protein protect against infection by inhibition of fusion. J. Infect. Dis. 204, 1692-1701 (2011)

132. Detalle, L. et al. Generation and characterization of ALX-0171, a potent novel therapeutic nanobody for the treatment of respiratory syncytial virus infection. Antimicrob. Agents Chemother. 60, 6-13 (2015).

133. Rossey, l. et al. Potent single-domain antibodies that arrest respiratory syncytial virus fusion protein in its prefusion state. Nat. Commun. 8, 14158 (2017).

This article describes the use of a single-domain antibody against RSV.

134. Hinton, P. R. et al. Engineered human $\lg G$ antibodies with longer serum half-lives in primates. J. Biol. Chem 279, 6213-6216 (2004). 
135. Dall'Acqua, W. F., Kiener, P. A. \& Wu, H. Properties of human IgG1s engineered for enhanced binding to the neonatal Fc receptor (FcRn). J. Biol. Chem. 281, 23514-23524 (2006).

136. Zalevsky, J. et al. Enhanced antibody half-life improves in vivo activity. Nat. Biotechnol. 28, 157-159 (2010)

137. Yu, X. Q. et al. Safety, tolerability, and pharmacokinetics of MEDI4893, an investigational, extended-half-life, anti-Staphylococcus aureus alphatoxin human monoclonal antibody, in healthy adults. Antimicrob. Agents Chemother. 61, e01020-16 (2017).

138. Ko, S. Y. et al. Enhanced neonatal Fc receptor function improves protection against primate SHIV infection. Nature 514, 642-645 (2014).

139. Gautam, R. et al. A single injection of anti-HIVantibodies protects against repeated SHIV challenges. Nature 533, 105-109 (2016)

140. Lazar, G. A. et al. Engineered antibody Fc variants with enhanced effector function. Proc. Natl Acad. Sci. USA 103, 4005-4010 (2006)

141. Presta, L. G. Molecular engineering and design of therapeutic antibodies. Curr. Opin. Immunol. 20, 460-470 (2008)

This is a review of strategies for enhancing antibody effector function.

142. Bowers, P. M. et al. Coupling mammalian cell surface display with somatic hypermutation for the discovery and maturation of human antibodies. Proc. Natl Acad. Sci. USA 108, 20455-20460 (2011).

143. Boder, E. T. \& Wittrup, K. D. Yeast surface display for screening combinatorial polypeptide libraries. Nat. Biotechnol. 15, 553-557 (1997).

144. McCafferty, J., Griffiths, A. D., Winter, G. \& Chiswell, D. J. Phage antibodies: filamentous phage displaying antibody variable domains. Nature 348 . 552-554 (1990).
145. Huse, W. D. et al. Generation of a large combinatorial library of the immunoglobulin repertoire in phage lambda. Science 246, 1275-1281 (1989).

146. Lee, E. C. et al. Complete humanization of the mouse immunoglobulin loci enables efficient therapeutic antibody discovery. Nat. Biotechnol. 32, 356-363 (2014).

147. Murphy, A. J. et al. Mice with megabase humanization of their immunoglobulin genes generate antibodies as efficiently as normal mice. Proc. Natl Acad. Sci. USA 111, 5153-5158 (2014).

148. Scheid, J. F. et al. A method for identification of HIV gp 140 binding memory B cells in human blood. J. Immunol. Methods 343, 65-67 (2009).

149. Lanzavecchia, A., Corti, D. \& Sallusto, F. Human monoclonal antibodies by immortalization of memory B cells. Curr. Opin. Biotechnol. 18, 523-528 (2007).

150. Huang, J. et al. Isolation of human monoclonal antibodies from peripheral blood B cells. Nat. Protoc. 8, 1907-1915 (2013)

151. Lee, J. H. et al. A broadly neutralizing antibody targets the dynamic HIV envelope trimer apex via a long, rigidified, and anionic beta-hairpin structure. Immunity 46, 690-702 (2017).

152. McCoy, L. E. \& Burton, D. R. Identification and specificity of broadly neutralizing antibodies against HIV. Immunol. Rev. 275, 11-20 (2017).

153. Dreyfus, C. et al. Highly conserved protective epitopes on influenza B viruses. Science 337, 1343-1348 (2012).

154. Corti, D. et al. Tackling influenza with broadly neutralizing antibodies. Curr. Opin. Virol. 24, 60-69 (2017).

155. Wu, N. C. \& Wilson, I. A. A. Perspective on the structural and functional constraints for immune evasion: insights from influenza virus. J. Mol. Biol. 429, 2694-2709 (2017).

156. Wen, X. et al. Structural basis for antibody crossneutralization of respiratory syncytial virus and human metapneumovirus. Nat. Microbiol. 2, 16272 (2017).

\section{Acknowledgements}

The authors thank J. Mascola, D. Sok and M. Vasquez for comments on the manuscript. The authors also thank L. Hangartner and C. Corbaci for assistance with figure preparation. D.R.B. acknowledges the financial support from the US National Institute of Allergy and Infectious Disease, the International AIDS Vaccine Initiative, the Bill and Melinda Gates Foundation and the Ragon Institute.

\section{Competing interests statement}

The authors have no competing interests.

Author contributions

Both authors contributed to research and discussion of the content of the article and to writing, reviewing and editing of the manuscript before submission.

\section{Publisher's note}

Springer Nature remains neutral with regard to jurisdictional claims in published maps and institutional affiliations.

\section{Reviewer information}

Nature Reviews Immunology thanks James Crowe Jr, Antonio Lanzavecchia and Gavin Screaton for their contribution to the peer review of this work.

\section{FURTHER INFORMATION}

The AMP study: https://ampstudy.org/about

ALL LINKS ARE ACTIVE IN THE ONLINE PDF 